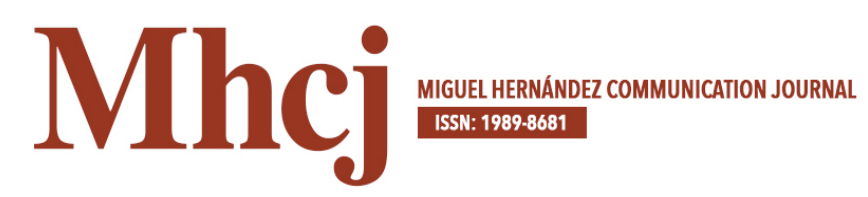

Fecha recepción: 09/04/2020

Fecha de publicación: 31/07/2020

\title{
Experiencias del cine documental en México
}

Francisco-Julián Martínez-Cano | francisco.martinezc@umh.es Universidad Miguel Hernández

Libro:

Estrada Álvarez, A., Defossé, N. y Zavala Scherer, D. (Coords.) (2019). Cine político en México

(1968-2017). New York: Peter Lang. Colección: Transamerican Film and Literature. ISBN:

978-1-4331-5744-8, 352 págs.

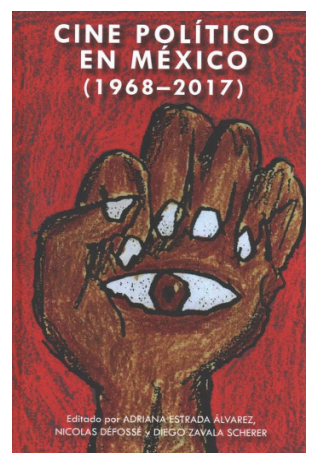

Cómo citar este texto:

Francisco-Julián Martínez-Cano (2020). Experiencias del cine documental en México, Miguel Hernández Communication Journal, Vol. 11 (2), pp. 339 a 344. Universidad Miguel Hernández, UMH (Elche-Alicante). DOI: http://dx.doi.org/10.21134/mhcj.v11i0.345

How to cite this text:

Francisco-Julián Martínez-Cano (2020). Experiences of documentary filmmaking in Mexico, Miguel Hernández Communication Journal, Vol. 11 (2), pp. 339 a 344. Universidad Miguel Hernández, UMH (Elche-Alicante). DOI: http://dx.doi.org/10.21134/mhcj.v11i0.345 
Cine Político en México (1968-2017) recoge la historia del cine mexicano fundamentalmente desde las experiencias de producciones documentales. Un género complejo de trabajar en el contexto social que se desarrolla, ya que mientras la ficción puede escudarse en la creatividad para desvelar o no momentos de la historia que hayan podido ser censurados, el género del documental no tiene esta posibilidad, sino que se espera realismo y veracidad:

El realismo en el documental no emplea la misma estética que el realismo de ficción, [...]. La función del realismo en ambos también difiere, mientras que en la ficción pretende camuflarse, en el documental pretende consolidar la conexión del texto con su referente, para posicionar al espectador en el lugar de aquello que acontece (Martínez-Cano, et al. 2020: 115).

Complicado cuando la censura sobrevuela en todo momento las cabezas de los autores, cuando existe el riesgo real de que la vida corre peligro. Si a esto se le añaden las dificultades propias de investigar en México (Jurado, 2010), en lo que tiene que ver con el acceso y conservación de algunos fondos documentales, resulta muy significativo el contenido que presenta este libro.

Los coordinadores de este número de la colección Transamerican Film and Literature, Adriana Estrada, Nicolas Défossé y Diego Zavala demuestran gran dominio del tema que tratan, como puede verse en los textos que firman, y una excelente elección en la selección de los capítulos que finalmente componen este volumen.

Aporta una novedad muy significativa: además de los textos académicos incluidos en el bloque denominado Miradas; se presenta otro titulado Experiencias, que supone toda una novedad en este tipo de estudios. La combinación de ambos modelos de textos, los academicistas y los ensayos experienciales sobre la práctica del género documental en el contexto de México, es sin lugar a dudas el elemento que convierte a este libro en indispensable en las bibliotecas de cine de este país.

En el primer bloque se incluyen los siguientes títulos y autores: capítulo 1, Una mirada al 68 mexicano en pantalla, a cargo de Adriana Estrada Álvarez; capítulo 2, Puentes audiovisuales, La rebelión del Ejército Zapatista de Liberación Nacional, el video independiente, de Claudia Magallanes Blanco; capítulo 3, El cine político como militancia, de Livia K. Stone; María Paz Amaro Cavada es la autora del capítulo 4, Maya Goded y Sarah Minter. Aproximaciones de la vida a través del lente. En el capítulo 5 se titula Documental, duelo, testimonio y acción política, a cargo de Diego Zavara Scherer; el capítulo 6, La representación de la violencia del narco en el reciente cine mexicano, a cargo de Javier Ramírez Miranda. El capítulo 7 de David M.J. Wood lleva por título Nombrar lo ausente, David M.J. Wood; y finalmente el 8, Invertir la mirada. Migrante y cine, de Nicolás Défossé. 
Nos detenemos con especial interés en la segunda parte, por la dificultad y la novedad de que los propios autores expliquen sus experiencias en un libro a todos visos de corte científico, en el ámbito de las ciencias sociales. Sus autores escriben en primera persona porque son sus vivencias, como si se tratase de una entrevista en la que sólo hay una única pregunta y pueden contestar con toda libertad.

Para este bloque se ha optado por un formato acorde a su contenido, de cara a no perder el protagonismo que merecen sus firmas. Por este motivo se han seleccionado algunas de las frases más significativas. El objetivo es no perder la fuerza de la primera persona. En esta selección no hay método, hay sólo intención de captar la esencia del mensaje del autor. Sí, la selección es subjetiva, pero pretende ser el elemento crítico de la reseña que se presenta, dejando como un final abierto al lector, para que forme su opinión, y en definitiva, para animarlo a la lectura.

En el capítulo 9, jLos cortometrajes son de quienes los trabajan!, Gregory Beger habla del formato del cortometraje y de sus posibilidades en el caso de los mexicanos. "Si quieres cambiar el mundo, el cortometraje es simplemente una herramienta para hacer algo que da verdadero poder a la gente común y corriente: el trabajo comunitario" (p. 177). Y esta otra, que también resulta relevante: "Los mexicanos tenemos una herramienta en nuestras manos poco explotada: el nuevo video viral" (p. 190).

En el capítulo 10, La jaula de oro, Diego Wudama-Díez entrega su alma en un texto lleno de sentimiento y pasión para animar a contar historias reales: "generar contenidos que estimulen el análisis profundo y la conciencia, que hagan nuestra existencia más plena, más verdadera. Y añade más adelante que "a pesar de que los muros no caigan todavía, mantener la esperanza en que nuestras pequeñas obras algún efecto van a tener, saber que nuestras creaciones generan surcos en el agua, entre otras cosas, porque estamos vivos" (p. 214).

En el capítulo 11, Filmar Guerrero, el camino de las cuatro vertientes, de Ludovic Bonleux, destacamos una reflexión del autor que dice mucho del enfoque de sus trabajos: "prefiero tener un cuadro un poco sucio, pero adentro del cual pase algo espontáneo, que una imagen muy limpia de una reconstrucción (...) para un documental” (p. 227).

En el capítulo 12, Proyectar el ch'ulel a través del cine, de María Sojob, resulta inolvidable y reflexiva su afirmación final: "queremos retornar a la sabiduría de nuestros padres y madres y hablar desde ahí, (...) con conciencia, con alma, pues todo aquello que no tiene ch'ulel no está vivo” (p. 239). 
Indira Cato, en el capítulo 13, De amores que te llevan, hace una afirmación al inicio de su texto muy significativa: "Hacer documentales puede ser un gran acto político, y en México casi una guerrilla". Un generoso espacio donde la autora da voz a otros profesionales con los que ha trabajado y las dificultades que se han encontrado en el quehacer de su trabajo.

En el capítulo 14, El documental y su circunstancia, Mario Viveros Barragán aporta una afirmación que siempre hay que tener presente: "Pienso que la experiencia del trabajo fílmico aporta, (...) al proceso de creación artista, sino también al de saber-conocimiento” (p. 258).

En el capítulo 15, A la altura de los ojos, de Roberto Olivares, tiene una carga de contenido reflexivo prácticamente en cada uno de los párrafos. En todo el texto se respira la necesidad de obligado cumplimiento de conocernos a nosotros mismos para poder construir un futuro. Aprender de los errores y aprender de lo desconocido para que deje de serlo serían quizás dos comunes denominadores en todo el capítulo.

Este autor, lleva a cabo una autocrítica de la sociedad mexicana que requiere de una llamada de atención que va más allá del tratamiento audiovisual: "los mexicanos no nos vemos con claridad cuando nos miramos al espejo (...). Y es complicado saber a dónde queremos ir si no entendemos primero quiénes somos" (p. 285).

En el capítulo 16, Especulando sobre la realidad, Emiliano Altuna pone el dedo en la llaga de las dificultades de hacer un cine objetivo ante un contexto de autocomplacencia, apela a la necesidad de contar la realidad y apostar por un cine que genere preguntas.

En el capítulo 17, Los llamados de la realidad, Mauricio Bidault retoma de nuevo la temática de la delincuencia organizada y el narcotráfico, y explica que sus trabajos le permiten ver en primera persona las consecuencias que los crímenes tienen en una comunidad y ver más allá, "porque detrás de cada muerto, de cada desaparecido de esa cuenta que no deja de aumentar, queda una familia, un barrio, un círculo que se rompe y debilita" (p. 299).

En el capítulo 18, Istmeño, viento de rebeldía, Alèssi Dell’Umbria describe su proceso de aprendizaje trabajando en proyectos con los indígenas y de como "el aspecto didáctico tampoco debe dominar todo el documento. Hacía falta equilibrarlo con escenas de vida donde el espíritu indígena se desplegara en toda su inmanencia” (p. 324).

En el capítulo 19, Descubrir y contar las historias que nos rodean, Lucía Gajá es constante en la importancia de mantener siempre la esencia que provocó que quisiéramos contar una historia, 
cualquiera que sea su formato. El fragmento que seleccionamos es ejemplar para cerrar este bloque de experiencias:

Considero fundamental tener siempre presente la semilla de las obras que realizamos, ya sean películas, libros, canciones o pinturas. Guardar ese preciso momento en el que denota una idea y ya no se puede ir, atesorar la fuente principal que hizo surgir la necesidad de contar algo y lo que hace que se conecte a nosotros (Gajá, 2019: 334).

A pesar de todas sus virtudes, es criticable la ausencia de mención a los festivales de cine, tan fundamentales en la promoción de los contenidos audiovisuales fuera del ámbito comercial, y de los propios realizadores como autores y creadores (Jurado, 2006) que precisamente son el perfil de los que aquí se exponen, tanto de los ejemplos que se dan en la primera parte, como de los datos en la segunda, ya sea como ejemplos o como experiencias propias de sus autores. Sin duda, esta es una buena excusa para un número especializado en festivales de cine en México y sus funciones.

\section{Bibliografía:}

Estrada Álvarez, A., Defossé, N. y Zavala Scherer, D. (Coords.) (2019). Cine político en México (1968-2017). New York: Peter Lang. Colección: Transamerican Film and Literature. ISBN: 978-14331-5744-8, 352 págs.

Jurado-Martin, M. (2010). La investigación académica sobre periodismo en México: una mirada crítica. En Revista Mediterránea de Comunicación, 1, pp. 141-157. Recuperado de https://rua.ua.es/ dspace/bitstream/10045/14329/1/ReMedCom 01 08.pdf

Jurado-Martin, M. y Nieto Martín, A. (2014). Nuevas propuestas, viejos circuitos: El papel de los festivales de cine españoles en la consolidación de los nuevos realizadores. En Revista de historia del cine. 1134-6795. Recuperado de: $\underline{\text { shorturl.at/hqO15 }}$

Martínez-Cano, F., Ivars-Nicolás, B., \& Roselló-Tormo, E. (2020). Cine memoria. Intersecciones entre documental y ficción en la práctica cinematográfica latinoamericana contemporánea: estudio de caso de Roma. Fotocinema. Revista cientifica de cine y fotografía, 0(20), 111-136. doi: http://dx.doi. org/10.24310/Fotocinema.2020.v0i20.7594 
MHCJ Vol. 11 (2) | Año 2020 - Reseña n 1 (10) - Páginas 339 a 344 - mhjournal.org

\section{(c) (1) (2)}

Licencia Creative Commons

Miguel Hernández Communication Journal

mhjournal.org

\section{Cómo citar este texto:}

Francisco-Julián Martínez-Cano (2020). Experiencias del cine documental en México, Miguel Hernández Communication Journal, Vol. 11 (2), pp. 339 a 344. Universidad Miguel Hernández, UMH (Elche-Alicante).

DOI: http://dx.doi.org/10.21134/mhcj.v11i0.345 